\title{
Abnormal Nonshivering Thermogenesis in Mice with Inherited Defects of Fatty Acid Oxidation
}

\author{
Carmen Guerra, ${ }^{\star}$ Robert A. Koza, ${ }^{\star}$ Kathryn Walsh, ${ }^{\star}$ David M. Kurtz, ${ }^{\ddagger}$ Philip A. Wood, ${ }^{\ddagger}$ and Leslie P. Kozak \\ $*$ The Jackson Laboratory, Bar Harbor, Maine 04609; and ${ }^{\ddagger}$ Department of Comparative Medicine, University of Alabama, Birmingham, \\ Alabama 35294
}

\begin{abstract}
When placed in the cold $\left(4^{\circ} \mathrm{C}\right), \mathrm{BALB} / \mathrm{cByJ}$ mice of both genders rapidly lose body temperature as compared with the control strain, C57BL/6J. This sensitivity to cold resembles that previously described for mice with a defect in nonshivering thermogenesis due to the targeted inactivation of the brown adipocyte-specific mitochondrial uncoupling protein gene, Ucp1. Genetic mapping of the trait placed the gene on chromosome 5 near Acads, a gene encoding the short chain acyl CoA dehydrogenase, which is mutated in $\mathrm{BALB} / \mathrm{cByJ}$ mice. The analysis of candidate genes in the region indicated a defect only in the expression of Acads. Confirmation of the importance of fatty acid oxidation to thermogenesis came from our finding that mice carrying the targeted inactivation of the long chain acyl CoA dehydrogenase gene ( $A c a d l$ ) are also sensitive to the cold. Both of these mutations attenuate the induction of genes normally responsive to adrenergic signaling in brown adipocytes. These results suggest that the action of fatty acids as regulators of gene expression has been perturbed in the mutant mice. From a clinical perspective, it is important to determine whether defects in thermogenesis may be a phenotype in human neonates with inherited deficiencies in fatty acid $\beta$-oxidation. (J. Clin. Invest. 1998. 102:1724-1731.) Key words: thermogenesis - gene mutations • short and long chain acyl CoA dehydrogenase $\bullet$ mitochondrial uncoupling protein
\end{abstract}

\section{Introduction}

The production of heat by brown adipose tissue (BAT) $)^{1}$ is accomplished by a specialized mechanism called nonshivering thermogenesis (1). An electron motive force established across the inner mitochondrial membrane during respiration is dissi-

\footnotetext{
Address correspondence to Dr. Leslie P. Kozak, Pennington Biomedical Research Center, 6400 Perkins Road, Baton Rouge, LA 70808. Phone: 504-763-2771; FAX: 504-763-2525; E-mail: kozaklp@mhs.pbrc.edu

Received for publication 9 July 1998 and accepted in revised form 15 September 1998.
}

1. Abbreviations used in this paper: $\mathrm{B} 6, \mathrm{C} 57 \mathrm{BL} / 6 \mathrm{~J}$ mice; $\mathrm{BAT}$, brown adipose tissue; LCAD, long chain acyl CoA dehydrogenase; MCAD, medium chain acyl CoA dehydrogenase; PPAR, peroxisome proliferator activated receptor; SCAD, short chain acyl CoA dehydrogenase; UCP1, mitochondrial uncoupling program; VLCAD, very long chain acyl CoA dehydrogenase.

J. Clin. Invest.

(C) The American Society for Clinical Investigation, Inc. 0021-9738/98/11/1724/08 \$2.00

Volume 102, Number 9, November 1998, 1724-1731

http://www.jci.org pated as heat by the mitochondrial uncoupling protein (UCP1) rather than being used to drive the synthesis of ATP (2). An essential role for UCP1 in this process, first deduced from biochemical analyses by Ricquier and Kader (3) and Heaton et al. (4), was recently established by the targeted inactivation of the Ucpl gene in mice (5). Mice homozygous for the inactivated allele failed to maintain normal body temperature when exposed to the cold at $4^{\circ} \mathrm{C}(5)$. Similarly, the inactivation of the dopamine $\beta$-hydroxylase gene results in mice deficient in norepinephrine and extremely sensitive to the cold, indicating that the adrenergic signal transduction is essential for nonshivering thermogenesis (6). However, several experimental observations indicate that mechanisms controlling thermogenesis may be more complicated than the gene-targeting experiments suggest. Genetic models of obesity, including Lep/Lep and Lepr/ Lepr mice, do not survive exposure to cold (7), despite the fact that the Ucp1 gene can be induced to normal levels of expression during this exposure to the cold (8). However, Lep/Lep and Lepr/Lepr mice can tolerate exposure to the cold if they are acclimated slowly (9), as can the Ucp1 KO mice (Koza, R.A., and L.P. Kozak, unpublished observations).

Accordingly, the mechanisms associated with adaptation to the cold need to be explored further to identify how other factors are implicated in the control of nonshivering thermogenesis and brown fat differentiation. Most important is the evidence that thyroid hormone is required for induction of Ucp1 expression (10) as well as the transcription factors PPAR $\gamma$ and the CCAAT-enhancing binding protein- $\alpha$, which have been implicated in the process from the analysis of the Ucp1 gene enhancer region (11) and gene targeting experiments (12). We now report that spontaneous and induced mutations to the long chain acyl CoA dehydrogenase (LCAD) and short chain acyl CoA dehydrogenase (SCAD) genes in mice cause a sensitivity to cold similar to mice deficient in UCP1. The data indicate that, despite the fact that the family of dehydrogenase enzymes catalyzing the $\beta$-oxidation of fatty acids has overlapping catalytic specificity (13), defects in only one of the acyl CoA dehydrogenases results in major defects in thermogenesis. Given the abundance of brown fat in neonatal mammals, including humans (14), BAT may play a critical role in temperature regulation in human neonates and could be an important factor in the clinical syndromes seen in children with inherited defects of fatty acid oxidation.

\section{Methods}

Animals. BALB/cByJ, C57BL/6J (B6), and CXB recombinant inbred strains of mice and $\mathrm{BALB} / \mathrm{cBy}$ mice were obtained from the Production Colonies and the Mouse Mutant Resources of The Jackson Laboratory (Bar Harbor, ME), respectively. Backcross and intercross progeny of $\mathrm{BALB} / \mathrm{cByJ}$ and $\mathrm{B} 6$ mice were generated in the research colonies of L.P. Kozak. The genealogy of these strains is shown in Fig. 1. LCAD-deficient mice were generated in the laboratory of P.A. Wood from an intercross of B6,129/SvJ.Acadltm1Uab 


\section{Geneology of BALB/c Mice}

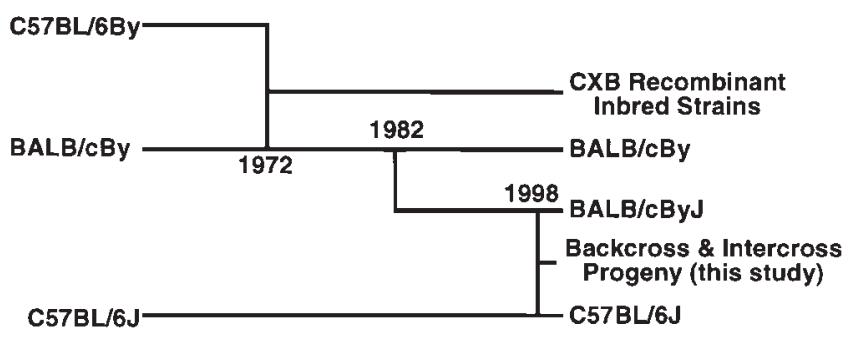

Figure 1. Genealogy of the BALB/c strains.

$(-/-)$ and B6,129/SvJ.Acadl $(+/+)$ mice at generation 2-3 (Kurtz, D.M., P. Rinaldo, W.J. Rhead, L. Tian, D.S. Millington, J. Vockley, D. Hamm, A.E. Brix, J.R. Lindsey, C.A. Pinkert, et al., manuscript submitted for publication). For Acadl gene targeting, TC-1 ES cells and C57BL/6NtacfBR mice were obtained from Taconic Farms Inc. (Germantown, NY).

Cold sensitivity. Cold sensitivity was assessed as described (5).

Time course cold exposure experiment. All mice were males $8 \mathrm{wk}$ of age. Differences in the induction of $U c p 1$ mRNA in BAT by cold were determined in BALB/cByJ (C) and C57BL/6J (B6) mice by a two-step procedure. First, mice were maintained at thermoneutrality $\left(29^{\circ} \mathrm{C}\right)$ for $1 \mathrm{wk}$ to reduce $U c p 1 \mathrm{mRNA}$ levels by minimizing the need for thermogenesis. Second, mice were then housed individually at $4^{\circ} \mathrm{C}$ in precooled cages, and after $0.5,2$, and $4 \mathrm{~h}$, of cold exposure, five animals from each strain were sacrificed by cervical dislocation, and BAT was removed for RNA isolation for Northern Blot analysis. In addition, five mice from each strain were sacrificed after $1 \mathrm{wk}$ at $29^{\circ} \mathrm{C}$ (considered time zero of cold temperature exposure) and at $22^{\circ} \mathrm{C}$ (standard mouse room temperature) to prepare RNA for analysis.

Histology. BAT was fixed in Bouin's solution. Paraffin-embedded sections were stained with hematoxylin and eosin.

Northern blots. Mice were sacrificed by cervical dislocation, and the tissues were frozen immediately in liquid nitrogen. Total RNA $(20 \mu \mathrm{g})$ was isolated by the guanidinium thiocyanate method (15). For some analyses of low abundant mRNAs, polyadenylated RNA was isolated by chromatography on oligo dT-cellulose (16). Northern blot analysis was conducted on $1.2 \%$ agarose- $1 \mathrm{M}$ formaldehyde gels as described by Derman et al. (17). Following hybridization and washing, signals were quantified first by the Fujix BAS1000 Bio-imaging Analyzer (Fuji Xerox Co., Ltd., Japan) and then by X-ray films and densitometry on the ImageQuant (Molecular Dynamics, Sunnyvale, CA). The cDNA derived hybridization probes used in this study were: Ucp1 (8), Ucp2 (5), Ucp3 (18), type II iodothyronine deiodinase (19), leptin (20), $\beta 1$ - and $\beta 3$-adrenergic receptors (generously provided by Dr. Sheila Collins), 18S RNA (21), $\beta$-adrenergic receptor kinase 2 (22), neuronal nitric oxide synthase (23), F1/Fo ATP synthase subunit e (24), SCAD (25), and LCAD (26).

Genome wide-scan and mapping strategy. To map the chromosomal location of the gene(s) involved in the cold-sensitive phenotype, we generated $(\mathrm{BALB} / \mathrm{cByJ} \times \mathrm{B} 6) \mathrm{F} 1 \times \mathrm{BALB} / \mathrm{cByJ}$ backcross and intercross (F2) progeny from the BALB/cByJ (cold-sensitive) and B6 (cold-resistant) strains. A genome-wide scan using 80 MIT microsatellite markers distributed at $15-20 \mathrm{cM}$ intervals was carried out with 15 cold-sensitive and 15 cold-resistant F2 mice using the DNA pooling method developed by Taylor (27). The region of interest on chromosome 5 was analyzed in detail by individually genotyping 100 intercross and 24 backcross mice. The CXB recombinant inbred strains (four male mice per line) were also used to map the gene(s) conferring cold sensitivity. Primers for amplification of microsatellites by PCR were obtained from Research Genetics, Inc. (Huntsville, AL).

A method for separating PCR products using horizontal PAGE was developed by Dr. Wendy A. Pitman at The Jackson Laboratory (unpublished data). Essentially, a 5\% (19:1 bis) acrylamide solution in $1 \times \mathrm{TBE}$ is polymerized with $0.8 \mathrm{ml}$ of $10 \%$ ammonium persulfate and $0.4 \mathrm{ml}$ of TEMED/100 $\mathrm{ml}$ of gel solution. After PCR samples are loaded, the polyacrylamide gels are run at $200 \mathrm{~V}$, post-stained with 20 $\mu \mathrm{l}$ of a $10 \mathrm{mg} / \mathrm{ml}$ ethidium bromide solution in $100 \mathrm{ml}$ of distilled $\mathrm{H}_{2} \mathrm{O}$, and DNA bands are detected using an ultraviolet source.

\section{Results}

Genetics of cold sensitivity. We have recently shown that inactivation of the Ucp1 gene on a C57BL/6J $\times 129 / \mathrm{SvPas}$ genetic background by gene targeting produces mice intolerant to cold. A second, independent targeted inactivation of Ucp1 was made in BALB/cByJ (Kozak, L.P., unpublished results). Surprisingly, on this genetic background, both the mutant and the wild-type mice were sensitive to the cold. In Fig. 2, we show the kinetics of cold sensitivity in B6 and BALB/cByJ mice. Body temperature in most BALB/cByJ mice dropped $10^{\circ} \mathrm{C}$ in less than $4 \mathrm{~h}$ at $4^{\circ} \mathrm{C}$, with none able to maintain body temperature for longer than $8 \mathrm{~h}$ in the cold; whereas B6 mice maintained their body temperature indefinitely under these conditions. The cold-sensitive phenotype is independent of the gender of the animal. We initiated a genetic analysis to determine the basis of the sensitivity to cold. F1 progeny between B6 (the cold-resistant strain) and BALB/cByJ mice (the cold-

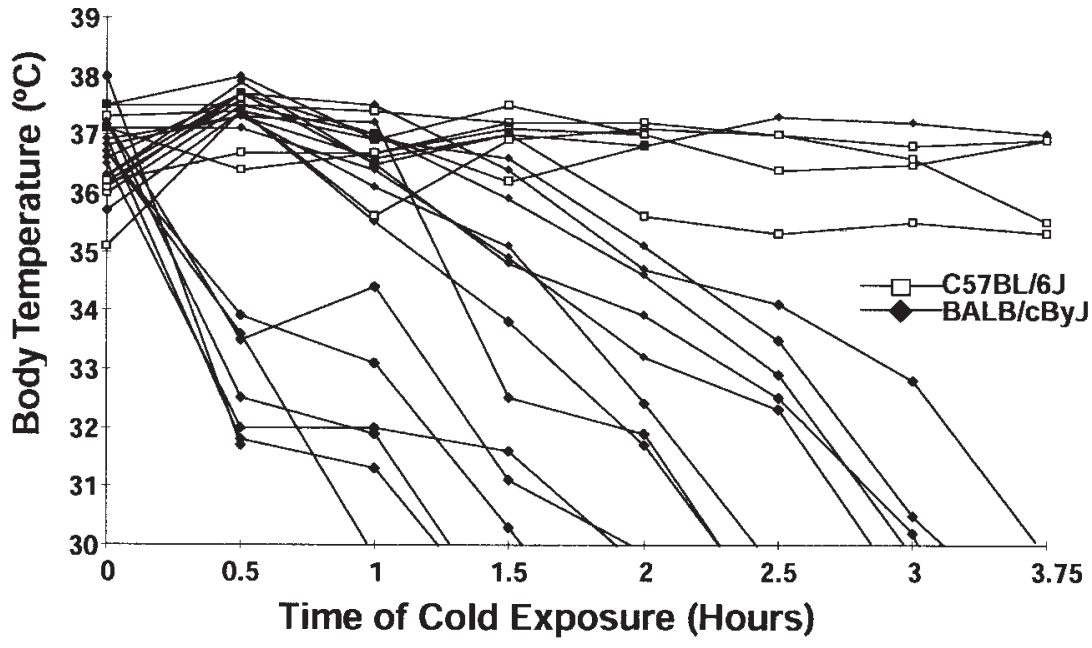

Figure 2. Changes in body temperature in BALB/ $\mathrm{cByJ}(\bullet)$ and $\mathrm{C} 57 \mathrm{BL} / 6 \mathrm{~J}(\bullet)$ mice during exposure to $5^{\circ} \mathrm{C}$ of cold. 


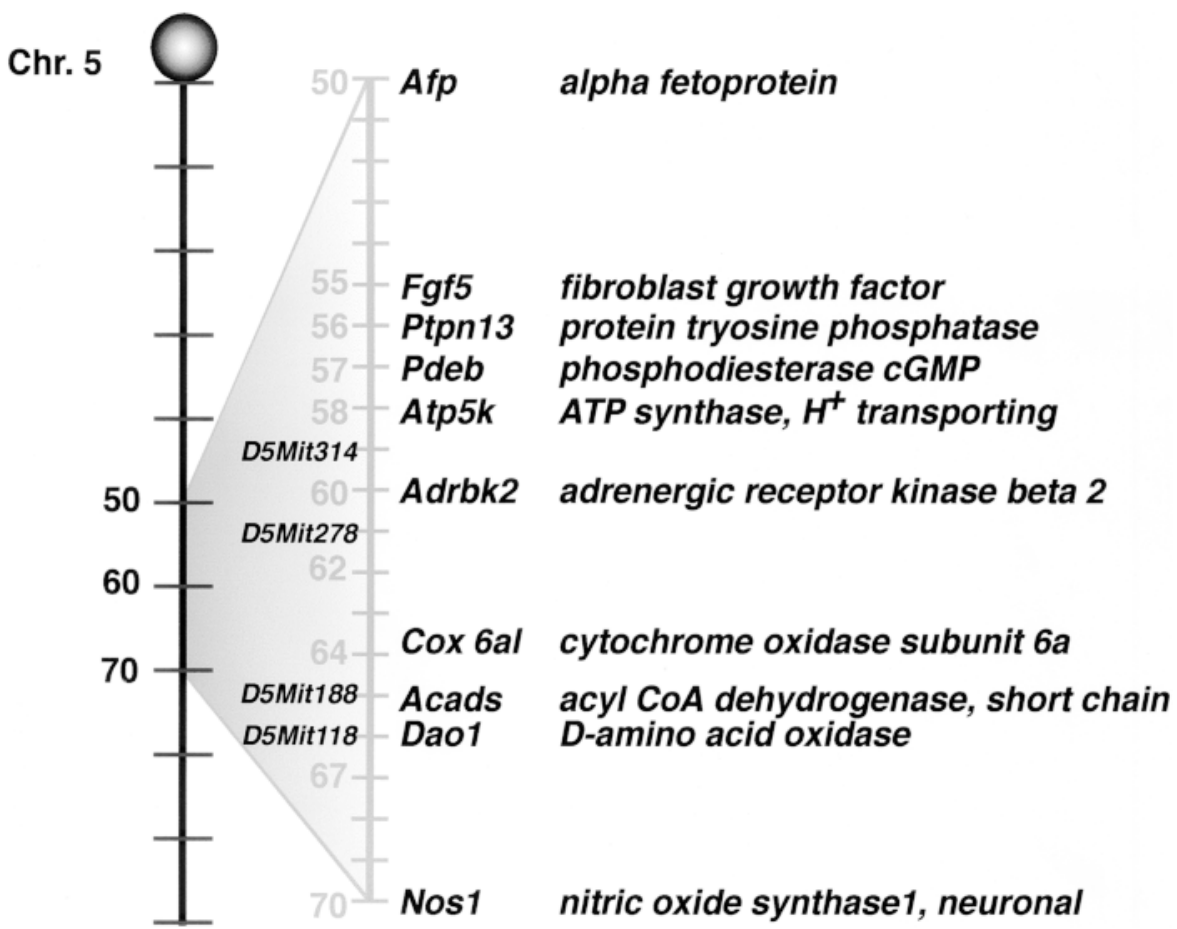

\begin{abstract}
Figure 3. Mapping of the cold-sensitive phenotype in BALB/cByJ mice. Cold sensitivity was mapped to chromosome 5 with MIT microsatellite markers and a polymorphism of Acads. No recombinants were detected between D5Mit188 and Acads. That 2 of 130 mice had a phenotype not predicted from the genotype at Acads places the gene controlling cold sensitivity to a region within $2 \mathrm{cM}$ of Acads.
\end{abstract}

sensitive strain) were cold resistant, whereas approximately $25 \%$ (22 of 106) of the F2 mice were cold sensitive and $50 \%$ (13 of 24) backcross $(\mathrm{BALB} / \mathrm{cByJ} \times \mathrm{B} 6) \mathrm{F} 1 \times \mathrm{BALB} / \mathrm{cByJ}$ mice were sensitive to cold. This distribution of phenotypes suggests that a single recessive gene controls cold sensitivity. A genome-wide scan using the DNA pooling method with 15 sensitive and 15 resistant mice from the F2 cross showed significant association of the cold-sensitive phenotype with the D5Mit7 marker, positioned at approximately $50 \mathrm{cM}$ on chromosome 5.

To define more precisely the linkage on chromosome 5, 106 F2 mice and 24 backcross mice were individually analyzed with a series of MIT markers in the region of interest. The region was narrowed down to about $14 \mathrm{cM}$, between 54 and 68 cM (Fig. 3). Several possible candidate genes that could be in- volved in the regulation of thermogenesis have been localized within this region. These genes included beta adrenergic receptor kinase type II (Adrbk2; $64 \mathrm{cM})$ and SCAD (Acads; 65 $\mathrm{cM})$. Two other genes, F1/Fo ATP synthase subunit e (Atp5k) at $50 \mathrm{cM}$ and neuronal NOS (NosI) at $70 \mathrm{cM}$, located slightly outside the region, were also tested as possible candidate genes. The position of these candidate genes is shown on the chromosome 5 linkage map (Fig. 3).

Alterations in the expression of the four candidate genes on chromosome 5 were assessed by Northern blot analysis of RNA isolated from the brain and brown fat of B6 and BALB/ cByJ mice (Fig. 4). Only the Acads gene showed a difference in the pattern of RNA expression. An RNA species of smaller size was detected in BALB/cByJ mice, while B6 showed a single strong band (Fig. 5). This variant expression of the Acads
BARK2
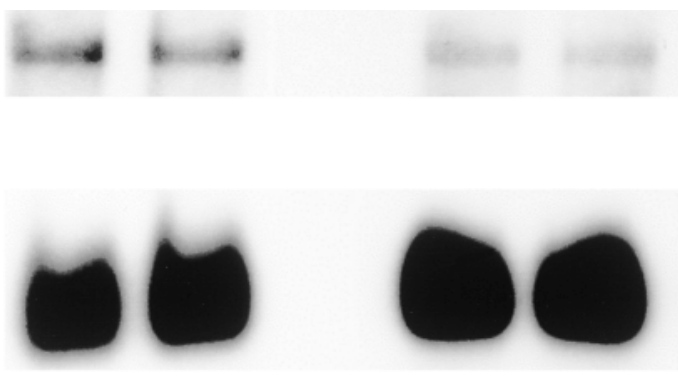

nNOS

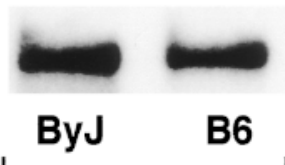

Brain
Figure 4. Analysis of candidate genes on chromosome 5 for variant expression in cold-sensitive $\mathrm{BALB} / \mathrm{cByJ}$ mice. Poly $(\mathrm{A})^{+}$RNA from the brain and brown adipose tissue was analyzed by Northern blot analysis as described in Methods. BARK2, $\beta$-adrenergic receptor kinase 2 ; nNos, neuronal nitric oxide synthase; ByJ, BALB/cByJ; B6, C57BL/6J. 
BALB/cByJ

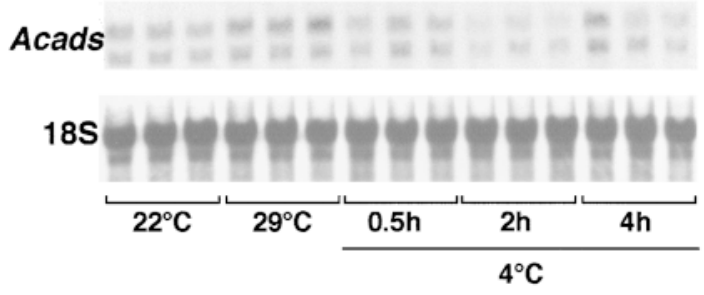

C57BL/6J

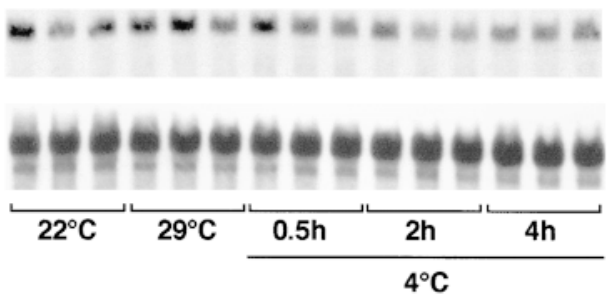

Figure 5. Abnormal expression of mRNA encoding SCAD in the brown fat of $\mathrm{BALB} / \mathrm{cByJ}$ mice under various conditions of environmental temperature. Northern blots of RNA were hybridized to the indicated probes.
RNA has been well described $(28,29)$. It results from the deletion of $278 \mathrm{bp}$ of the gene that includes part of intron 8, exon 9, intron 9, and part of exon 10. The deletion causes missplicing of the RNA and abolishes the production of functional enzyme activity. Mice that carry the mutant allele can be identified by a PCR assay that gives a product of $870 \mathrm{bp}$ for the wildtype Acads allele and 592 bp for the mutant Acads allele. The mutation, first described as an activity null mutation (30), occurred in the BALB/cByJ subline of mice after it was separated from the original BALB/cBy subline around 1982 (31). These two lines are virtually coisogenic and provide a genetic aid for establishing the identity of the mutant gene. Accordingly, BALB/cBy mice were obtained from stocks at The Jackson Laboratory to evaluate the relationship between the deletion mutation at the Acads gene and the cold sensitivity phenotype. These BALB/cBy mice possessed the wild-type Acads allele and were resistant to the cold in a manner indistinguishable from C57BL/6J mice (data not shown). Consistent with this result is the fact that all $\mathrm{CXB}$ recombinant inbred mice are resistant to the cold. This result is predicted because the $\mathrm{CXB}$ recombinant lines were derived from the $\mathrm{BALB} / \mathrm{cBy}$ line before the mutation of $A c a d s$ in the BALB/cByJ line. All $\mathrm{F} 2$ and backcross mice, generated from the C57BL/6J and $\mathrm{BALB} / \mathrm{cByJ}$ cross and used to map the cold-sensitive phenotype to chromosome 5, were then tested for the presence of the wild-type or mutant Acads allele. Out of 24 backcross and 106 intercross progeny, 128 of 130 mice expressed the cold sensitivity predicted from the allele present at Acads; two heterozygous mice were sensitive to the cold. The most likely explanation is an error in phenotyping, which has on occasion been found to be due to internal physical injury caused by repeated insertion of the thermal probe. Nevertheless, we sought an independent assessment of the effect of mutations to components of the fatty acid $\beta$-oxidation pathway on thermoregulation in mice.

SCAD is a mitochondrial enzyme that catalyzes the first reaction in the $\beta$-oxidation of short-chain fatty acids (C4-C6). A mutation that inactivated this gene would reduce fatty acid oxidation, thereby limiting the availability of reducing equivalents to establish the electromotive force necessary for heat production by the uncoupling protein mechanism. Since the Acads gene is one of four acyl CoA dehydrogenases that participate in fatty acid oxidation, mutations to other members of the group may also affect thermogenesis. The recent generation of a targeted mutation to the LCAD (Acadl) has enabled us to establish further the role of fatty acid oxidation on nonshivering thermogenesis (Kurtz, D.M., P. Rinaldo, W.J. Rhead, L. Tian, D.S. Millington, J. Vockley, D. Hamm, A.E. Brix, J.R. Lindsey, C.A. Pinkert, et al., manuscript submitted for publication). Accordingly, Acadl mutant mice were ex- posed to the cold as described for BALB/cByJ mice. The five Acadl mutant mice tested were very sensitive to the cold, with rectal temperature dropping $10-15^{\circ} \mathrm{C}$ within $2 \mathrm{~h}$ (Fig. $6 a$ ). Accordingly, the Acadl targeted mutation produces a cold intolerance phenotype as severe as the Acads mutation. These data strongly indicate that mutations to acyl CoA dehydrogenases cause the cold sensitivity phenotype, and this strengthens our conclusion that cold sensitivity in $\mathrm{BALB} / \mathrm{cByJ}$ mice is caused by a mutation to Acads.

Effects on gene expression. While it is intuitive that mutations to the pathway that provides the fuel to produce heat would have serious consequences on thermoregulation, these mutations also provide an opportunity to evaluate other aspects of fatty acid action in the cell, particularly those associated with the regulation of gene expression. Genes studied encoded: receptors that could be involved in cold stimulation, such as $\beta 1$ - and $\beta 3$-adrenergic receptors; Ucp1, and 5' deiodinase type II, genes activated by adrenergic signaling; Ucp 2 and

a

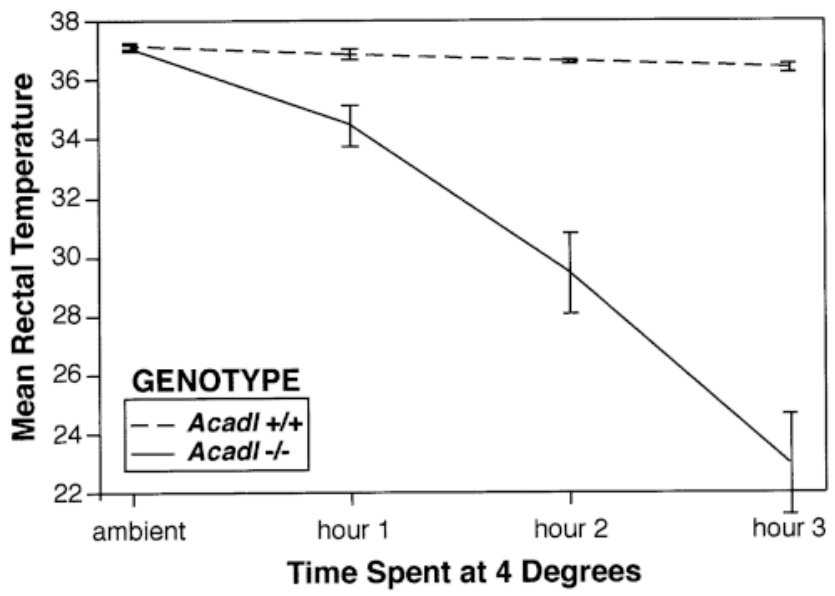

b

2 Hours at $4^{\circ}$

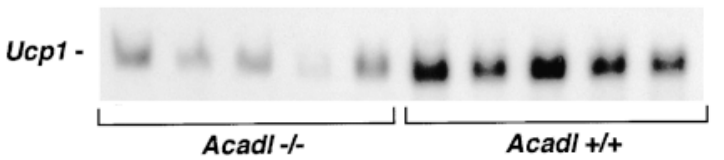

Figure 6. Cold sensitivity $(a)$ and $U c p 1$ expression $(b)$ in wild-type $(+/+)$ mice and mice homozygous for the inactivated Acadl (-/-) gene. 

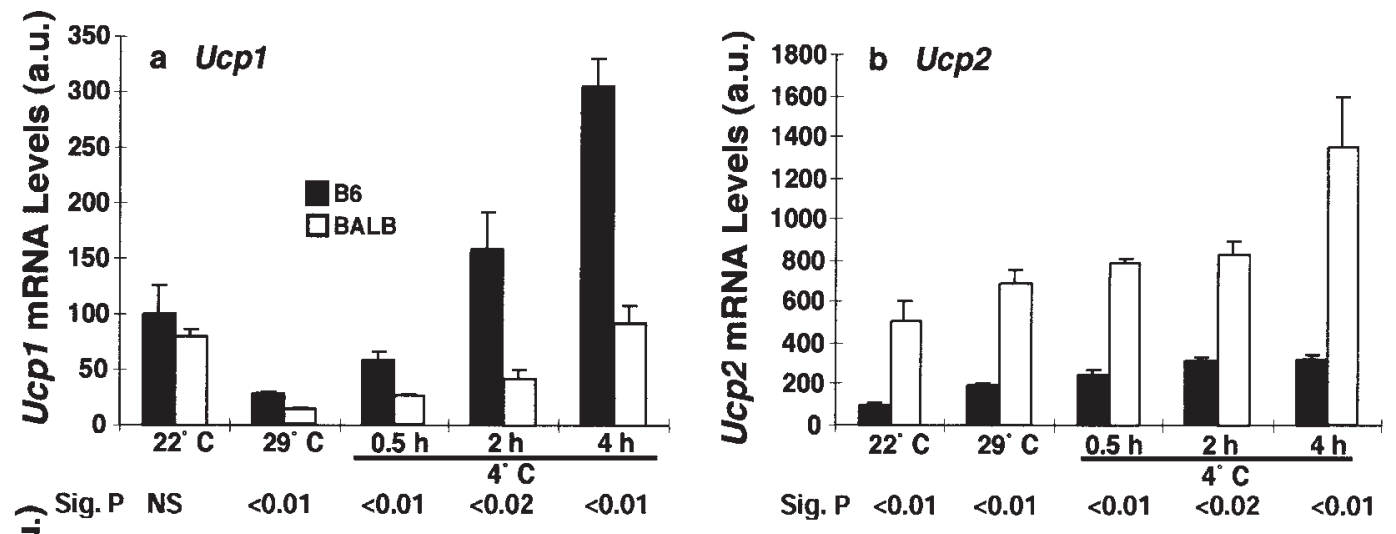

Figure 7. Patterns of expression of genes with thermogenic functions during the manipulation of the environmental temperature. Data are presented as the mean \pm the standard error of the density signals from Northern blots of total RNA isolated from the brown adipose tissue and analyzed by a Fuji Bioimager. Five male mice are present in each group. On the abscissa, $22^{\circ} \mathrm{C}$ is the temperature mice maintained in the

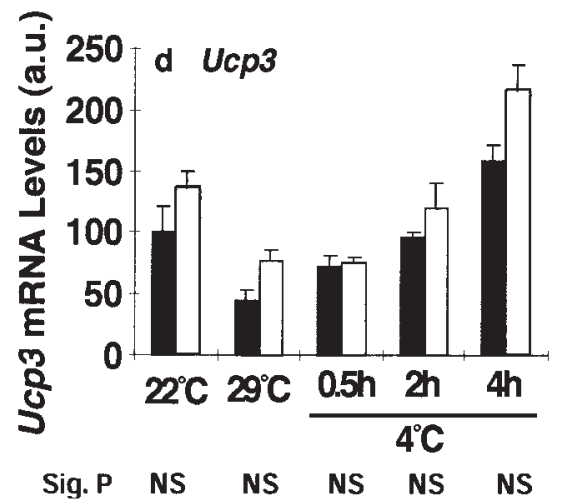
animal room, $29^{\circ} \mathrm{C}$ is a thermoneutral temperature at which mice were maintained for $7 \mathrm{~d}$ before being exposed to the cold $\left(4^{\circ} \mathrm{C}\right)$ for $0.5,2$, and $4 \mathrm{~h}$. The statistical significance of differences between B6 and BALB/ cByJ mice under any given condition was determined by an unpaired $t$ test (Statview version Sig. $\mathbf{P}$ $<0.01<0.05<0.05$

Sig. $P$ NS 4.57).

$U c p 3$, homologs of $U c p 1$ that may have a function in nonshivering thermogenesis; and Lep, a gene that is downregulated by adrenergic stimulation and that has been proposed to be a stimulator of energy expenditure (32).

As previously observed, Ucp1 mRNA levels in BALB/ cByJ and B6 mice were not significantly different at room temperature, nor after $7 \mathrm{~d}$ at thermoneutrality, $29^{\circ} \mathrm{C}$ (Fig. 7). Ucp1 expression during the cold exposure was three times higher and was induced more rapidly in B6 than in BALB/cByJ $(P<$ $0.0002)$. A similar difference in the rate of induction of the type II $5^{\prime}$-deiodinase gene resulted in more than sixfold greater expression in B6 mice after $4 \mathrm{~h}(P<0.02)$. These patterns of expression indicate that the ability of adrenergic signal transduction to activate its target genes has been strongly blunted in BALB/cByJ mice. A similar effect on the expression of $U c p 1$ was also found to occur in mice carrying the targeted mutation to the gene encoding LCAD (Fig. $6 b$ ). In contrast, the expression of mRNA for $\beta 1$ - and $\beta 3$-adrenergic receptors involved in the regulation of the thermogenic activity of brown adipocytes was not significantly different between B6 and BALB/cByJ mice (Fig. 8). Thus, the effects of cold exposure on Ucpl and type 5'-DII gene induction may be determined at a site downstream of the adrenergic receptors.

Ucp 2 mRNA levels were increased by cold stimulation in both strains; however, these levels were higher at all the points in BALB/cByJ mice (Fig. 7). After $4 \mathrm{~h}$ at $4^{\circ} \mathrm{C}$, the levels were more than fourfold higher in BALB/cByJ $(P=0.003)$. No significant differences in $U c p 3$ expression levels were observed between these two strains (Fig. 7). Similar to Ucp2 expression, the levels of leptin mRNA (Fig. 8) were fivefold higher at $22^{\circ} \mathrm{C}$ in BALB/cByJ than in B6 $(P<0.05)$. At $29^{\circ} \mathrm{C}$, leptin mRNA increased to similar levels $(P=0.72)$, and then following exposure to the cold, the levels were reduced as previously reported (33). However, the leptin mRNA levels were threefold higher in $\mathrm{BALB} / \mathrm{cByJ}$ after $4 \mathrm{~h}$ of cold exposure $(P=0.02)$. Since it is known that leptin expression is suppressed by adrenergic signaling (33), these effects may reflect the blunted adrenergic action in the BALB/cByJ mice, possibly reflecting the reciprocal effects of the mechanism affecting $U c p 1$ and deiodinase gene expression.

Brown fat morphology. We have previously found that elevated expression of Ucp2 occurs in the brown fat of UCP1deficient mice (5) and in mice that overexpress the glycerol 3-phosphate dehydrogenase gene (34). In both of these genetic models, lipid hypertrophy occurs in the brown adipocytes. Since steatosis occurs in the liver of BALB/cByJ mice, we analyzed the brown fat of these mice histologically to determine whether lipid may also be accumulating in the adipocyte of the BALB/cByJ mice. The photomicrograph in Fig. 9 shows that brown adipocytes of $\mathrm{BALB} / \mathrm{cByJ}$ mice also accumulate more lipids than B6. As with the UCP1-deficient mice, an increase in lipid accumulation in the BAT of BALB/cByJ mice correlates with higher expression of Ucp2 (Fig. 7). The increase in Ucp2 and leptin also parallel each other (35). Although it is possible that Ucp2 overexpression in UCP1-deficient mice is part of a compensatory mechanism responsible for the resistance to obesity, nevertheless the higher Ucp2 expression that is present in BAT during acute exposure to cold failed to maintain body temperature of UCP1-deficient or $\mathrm{BALB} / \mathrm{cByJ}$ mice. 
a B1 Adrenergic Receptor

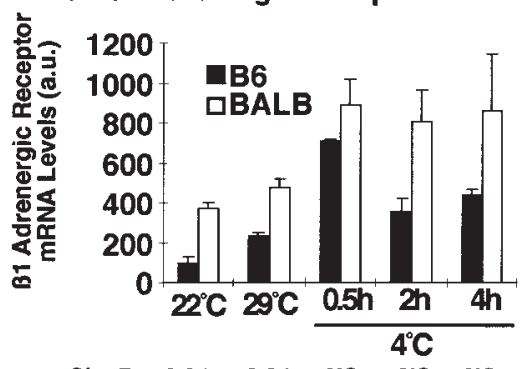

Sig. P $<0.01<0.01 \quad$ NS NS NS

b B3 Adrenergic Receptor
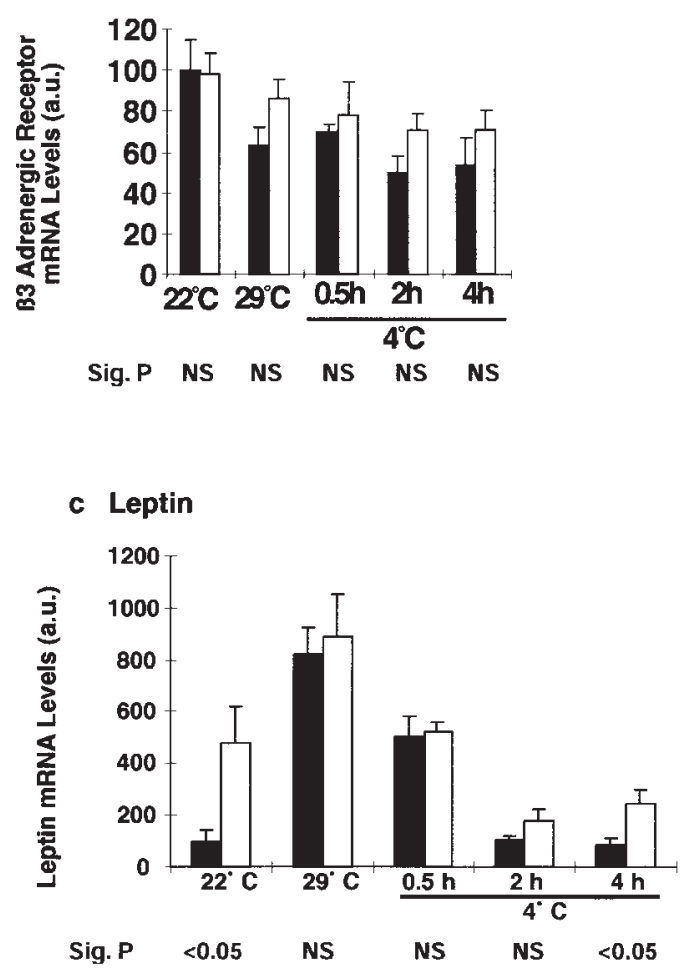

Figure 8. Patterns of expression of genes associated with signaling in brown adipocytes. Data were obtained and analyzed as described in legend to Fig. 6.

\section{Discussion}

We found that $\mathrm{BALB} / \mathrm{cByJ}$ cannot maintain body temperature when exposed to the cold at $4^{\circ} \mathrm{C}$. The similarity between the cold-sensitive phenotype of BALB/cByJ mice and that observed in mice with an inactive $U c p 1$ or in mice deficient in norepinephrine suggested that the cold sensitivity in the BALB/cByJ strain may also be caused by a defect in Ucp1 expression. Our strategy to determine the molecular defect causing the phenotype sought to determine the number of genes controlling the phenotype and to map the location of the gene(s). Although there was no reason to assume that the phenotype was the result of a mutation to a single gene, the genetic analysis showed that cold sensitivity in BALB/cByJ mice was controlled by a single gene located between 54 and $68 \mathrm{cM}$ on chromosome 5.

\section{a BALB/cByJ}

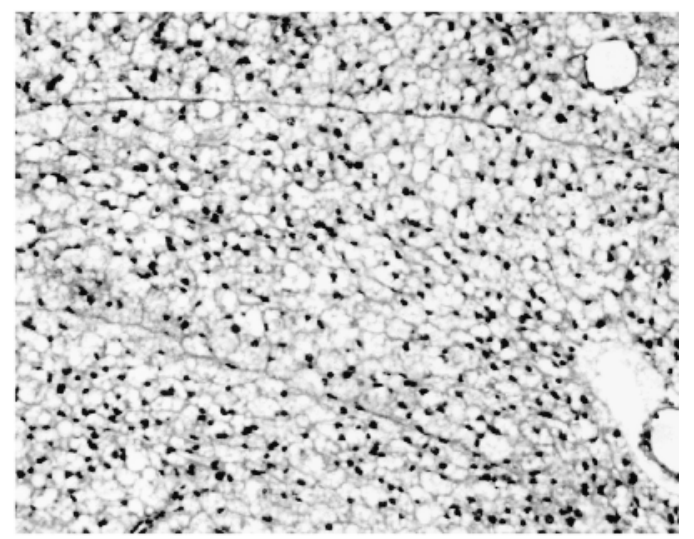

b B6

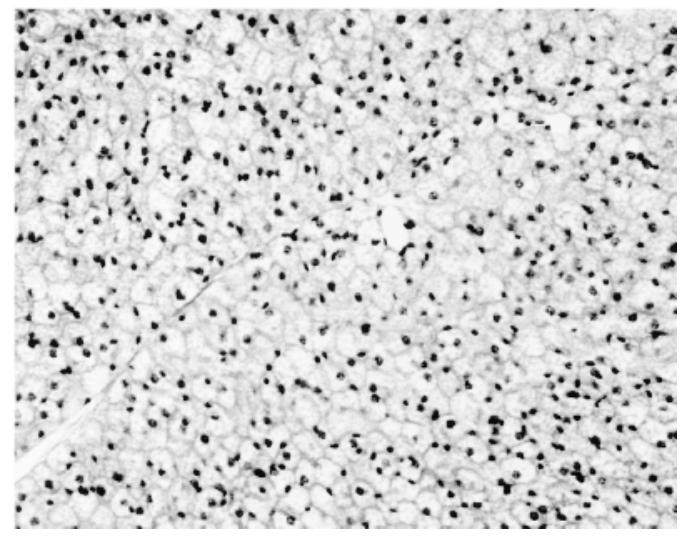

Figure 9. Comparison of lipid deposition in brown adipocytes of $\mathrm{BALB} / \mathrm{cByJ}(a)$ and $\mathrm{C} 57 \mathrm{BL} / 6 \mathrm{~J}(b)$ mice.

Several candidate genes reside in this region on chromosome 5 that could account for a defect in nonshivering thermogenesis. Of the four genes evaluated for defects in mRNA expression by Northern blot analysis, only the SCAD (Acads) gene showed an abnormal pattern of mRNA expression. A mutation of the Acads gene, located at $65 \mathrm{cM}$, has recently occurred in BALB/cByJ mice. The mutation has been characterized as a deletion of 278 bp near the $3^{\prime}$ end that causes missplicing of the RNA (29). No protein or biological activity can be detected in mutant mice (36). BALB/cBy sublines prior to 1982 have neither the mutant Acads gene nor the cold-sensitive phenotype. Thus, defects in one of the proteins associated with $\beta$-oxidation of fatty acids render mice cold sensitive. This conclusion has been greatly strengthened by our finding that mice in which the LCAD has been inactivated by gene targeting are also cold sensitive.

SCAD is one of four different acyl CoA dehydrogenase enzymes that catalyze the initial dehydrogenation of straightchain fatty acids in mitochondria. Three of them: SCAD, medium chain acyl CoA dehydrogenase (MCAD), and LCAD are soluble enzymes located in the mitochondria matrix as homotetramers. A fourth, the very long acyl CoA dehydrogenase (VLCAD) is attached to the inner membrane as a homodimer. Their name derives from the length of the fatty acids that they process. VLCAD and LCAD will shorten the long-chain fatty acids into medium-chain fatty acids that can then be processed 
by MCAD and SCAD (37). The SCAD, MCAD, and LCAD monomers share a high degree of homology between them but not with VLCAD. Except for LCAD, independent deficiencies in each of the straight-chain acyl CoA dehydrogenases has been described in humans (38). All of them are inherited as autosomal recessive traits. The SCAD-deficient mice show no overt clinical signs of disease; however, they develop a prominent fatty liver with hypoglycemia after fasting and accumulate and secrete fatty acid metabolites in the urine (36). In contrast, the SCAD deficiency in humans has more severe and variable clinical symptoms that include metabolic acidosis, chronic lipid storage myopathy, and neonatal hyperammonemic coma (38). Given that the LCAD- and SCAD-deficient mice are very sensitive to the cold, children deficient for any of the acyl CoA dehydrogenases could also be unusually sensitive to the cold. The potential importance of this phenotype in humans with deficiencies in mitochondrial $\beta$-oxidation is underscored by the fact that like most mammals, human neonates have high levels of brown fat, presumably for protection against exposure to the cold (14).

Fatty acid oxidation plays an important role in energy production. After sympathetic stimulation of brown adipocytes, there is activation of the hormone-sensitive lipase producing free fatty acids. Two important functions for free fatty acids in nonshivering thermogenesis have been postulated. First, free fatty acids directly interact with UCP1 in the mitochondrial inner membrane to establish a conformation that uncouples mitochondria respiration from the ATP synthesis. A model has also been advanced in which the fatty acids are transported by the uncoupling protein, the protons being passively associated with the fatty acids. Second, $\beta$-oxidation of fatty acids is the principal source of electrons for mitochondrial respiration. The failure of one or both processes could result in defective thermoregulation in BALB/cByJ mice or in LCAD-deficient mice. However, these metabolic events do not explain why induction of $U c p 1$ and the type II $5^{\prime}$-deiodinase genes were attenuated during cold exposure, nor why the expression of $U c p 2$ is enhanced. These effects on gene expression suggest a third role for fatty acids in the activation of nonshivering thermogenesis based upon emerging data that fatty acids could have a role as second messengers through the activation of the peroxisome proliferator activated receptors (PPARs). PPARs $(\alpha, \beta$, and $\gamma)$, members of the steroid nuclear receptor superfamily, have been shown to have tissue specificity and to be activated by various compounds, such as fibrates, thiazolidindiones, prostaglandins, and fatty acids (39-41). It has been shown that these nuclear factors have a very important role in the differentiation program of adipocytes in general and brown adipocytes in particular $(11,42)$. It is somewhat of a paradox that defects in fatty acid oxidation do not promote an increased expression of $U c p 1$, presuming that fatty acids build up in acyl CoA dehydrogenase deficiency and act as ligands for PPAR-mediated activation of gene expression. However, the upregulation of $U c p 2$ mRNA by fatty acids in the brown fat of mutant mice is consistent with the reported effects of PPAR $\gamma$ agonists on $U c p 2$ expression in cultured adipocytes (43). It is possible that free fatty acids are not elevated in the cytosol but may be efficiently converted to triglycerides, thus removing them as potential ligands. Alternatively, free fatty acids could act antagonistically toward functions of PPAR $\gamma$ in adipose tissue, rather than as the activator role they appear to have with PPAR $\alpha$ in hepatocytes (44). These mutant mice pro- vide an opportunity to establish the levels of free fatty acids and the state of PPAR $\gamma$ activation in the adipocyte in relation to alter the states of gene expression in vivo.

The role of PPAR transcription factors in fatty acid homeostasis is becoming evident from the phenotype associated with gene knockouts. Mice in which the PPAR $\alpha$ gene has been inactivated by gene targeting have reduced mRNA levels for several genes associated with mitochondria and peroxisomal fatty acid oxidation (45). An abnormally high hepatic lipid accumulation occurs in the PPAR $\alpha$ null mice that resembles the accumulation of lipids found in the livers of mice with an inactive Acads gene (36). Several genes that are associated with the fatty acid metabolism carry the response element motif that binds to PPAR and have severely reduced levels of expression in mice with an inactivated PPAR $\alpha$ gene (44). Accordingly, the physiological and morphological phenotype of mice is similar for the PPAR $\alpha$ and fatty acid acyl CoA dehydrogenase null mutants, suggesting that the genes are acting on common metabolic pathways. While lipid accumulation occurs in both the liver and brown fat of the fatty acid acyl CoA dehydrogenase-deficient mice, the SCAD-deficient BALB/cByJ mice do not appear to be susceptible to the development of obesity whether they are fed a standard or a high fat diet (L.P. Kozak, unpublished results).

In summary, we have demonstrated that intact fatty acid oxidation is essential for nonshivering thermogenesis. Disruption of this pathway markedly affects the expression of genes encoding functionally related proteins such as UCP1, UCP2, and T4-deiodinase. Given these results, we speculate that cold intolerance is a potentially important phenotype to be aware of in children with inborn errors of fatty acid oxidation.

\section{Acknowledgments}

We acknowledge the contributions of summer students, Laura Morges and Walker MacCormick, to the initial phases of this research.

This research was supported by funds from the National Institutes of Health, R01-HD08431 (L.P. Kozak) and R01-RR 02599 (P.A. Wood), and Pfizer Inc. (L.P. Kozak).

\section{References}

1. Smith, R.E., and B.A. Horwitz. 1969. Brown fat and thermogenesis. Physiol. Rev. 49:330-425.

2. Nicholls, D.G., and R.M. Locke. 1984. Thermogenic mechanisms in brown fat. Physiol. Rev. 64:1-64.

3. Ricquier, D., and J.-C. Kader. 1976. Mitochondrial protein alteration in active brown fat: a sodium dodecyl sulfate-polyacrylamide gel electrophoretic study. Biochem. Biophys. Res. Commun. 73:577-583.

4. Heaton, G.M., R.J. Wagenvoord, A. Kemp, and D.G. Nicholls. 1978. Brown adipose tissue mitochondria: photoaffinity labelling of the regulatory site of energy dissipation. Eur. J. Biochem. 82:515-521.

5. Enerbäck, S., A. Jacobsson, E.M. Simpson, C. Guerra, H. Yamashita, E.-M. Harper, and L.P. Kozak. 1997. Mice lacking mitochondrial uncoupling protein are cold-sensitive but not obese. Nature. 387:90-94.

6. Thomas, S.A., and R.D. Palmiter. 1997. Thermoregulatory and metabolic phenotypes of mice lacking noradrenaline and adrenaline. Nature. 387:94-97.

7. Trayhurn, P., and W.P.T. James. 1978. Thermoregulation and non-shivering thermogenesis in the genetically obese ob/ob mouse. Pfluegers Arch. 373: 189-193.

8. Jacobsson, A., U. Stadler, M.A. Glotzer, and L.P. Kozak. 1985. Mitochondrial uncoupling protein from mouse brown fat. Molecular cloning, genetic mapping, and mRNA expression. J. Biol. Chem. 260:16250-16254.

9. Coleman, D.L. 1982. Thermogenesis in diabetes-obesity syndromes in mutant mice. Diabetologia. 22:205-211.

10. Bianco, A.C., X. Sheng, and J.E. Silva. 1988. Triiodothyronine amplifies norepinephrine stimulation of uncoupling protein gene transcription by a 
mechanism not requiring protein synthesis. J. Biol. Chem. 263:18168-18175.

11. Sears, I.B., M.A. MacGinnitie, L.G. Kovacs, and R.A. Graves. 1996. Differentiation-dependent expression of the brown adipocyte uncoupling protein gene: regulation by peroxisome proliferator-activated receptor $\gamma$. Mol. Cell. Biol. 16:3410-3419.

12. Wang, N.D., M.J. Finegold, A. Bradley, C.N. Ou, S.V. Abdelsayed, M.D. Wilde, L.R. Taylor, D.R. Wilson, and G.J. Darlington. 1995. Impaired energy homeostasis in C/EBP alpha knockout mice. Science. 269:1108-1112.

13. Ikeda, I., K. Okamura-Ikeda, and K. Tanaka. 1985. Purification of short-chain, medium-chain and long-chain acyl-CoA dehydrogenases from rat liver mitochondria. J. Biol. Chem. 260:1311-1325.

14. Lean, M.E.J., and W.P.T. James. 1986. Brown adipose tissues in man. In Brown Adipose Tissue. P. Trayhurn and D.G. Nicholls, editors. Arnold, London. 339-365.

15. Chomczynski, P., and N. Sacchi. 1987. Single-step method of RNA isolation by acid guanidium thiocyanate-phenol-chloroform extraction. Anal. Biochem. 162:156-159.

16. Aviv, H., and P. Leder. 1972. Purification of biologically active globin messenger RNA by chromatography on oligothymidylic acid-cellulose. Proc. Natl. Acad. Sci. USA. 69:1408-1412.

17. Derman, E., K. Krauter, L. Walling, C. Weinberger, M. Ray, and J.E. Darnell, Jr. 1981. Transcriptional control in the production of liver-specific mRNAs. Cell. 23:731-739.

18. Vidal-Puig, A., G. Solanes, D. Grujic, J.S. Flier, and B.B. Lowell. 1997. UCP3: an uncoupling protein homologue expressed preferentially and abundantly in skeletal muscle and brown adipose tissue. Biochem. Biophys. Res. Commun. 235:79-82.

19. Croteau, W., J.C. Davey, V.A. Galton, and D.L. St. Germain. 1996. Cloning of the mammalian type II deiodinase. A selenoproetin differentially expressed and regulated in human and rat brain and other tissues. J. Clin. Invest. 98:405-417.

20. Zhang, Y., R. Proenca, M. Maffei, M. Barone, L. Leopold, and J.M. Friedman. 1994. Positional cloning of the mouse obese gene and its human homologue. Nature. 372:425-432.

21. Hwang, S.-Y., L.E. Benjamin, B. Oh, J.J. Rothstein, S.L. Ackerman, R.S.P. Beddington, D. Solter, and B.B. Knowles. 1996. Genetic mapping and embryonic expression of a novel, maternally transcribed gene Mem3. Mamm. Genome. 7:586-590.

22. Arriza, J.L., T.M. Dawson, R.B. Simerly, L.J. Martin, M.G. Caron, S.H. Snyder, and R.J. Lefkowitz. 1992. The G-protein receptor kinases beta-ARK1 and beta-ARK2 are widely distributed at synapses in rat brain. J. Neurosci. 12: 4045-4055.

23. Ogura, T., T. Yokoyama, H. Fujisawa, Y. Kurashima, and H. Esumi. 1993. Structural diversity of neuronal nitric acid synthase mRNA in the nervous system. Biochem. Biophys. Res. Commun. 193:1014-1022.

24. Swartz, D.A., E.I. Park, W.J. Visek, and J. Kaput. 1996. The e subunit of murine F1F0-ATP synthase. J. Biol. Chem. 271:20942-20948.

25. Kelly, C.L., M.E. Hinsdale, and P.A. Wood. 1993. Cloning and characterization of the mouse short-chain acyl-CoA dehydrogenase cDNA. Genomics. 18:137-140.

26. Hinsdale, M.E., S.C. Farmer, K.R. Johnson, M.T. Davisson, D.A. Hamm, R.J. Tolwani, and P.A. Wood. 1995. RNA expresssion and chromosomal location of the mouse long-chain acyl-CoA dehydrogenase gene. Genomics. 28:163-170.

27. Taylor, B.A., and S.J. Phillips. 1996. Detection of obesity QTLs on mouse Chromosomes 1 and 7 by selective DNA pooling. Genomics. 34:389-398.

28. Hinsdale, M.E., C.L. Kelly, and P.A. Wood. 1993. Null allele at Bcd-1 locus in BALB/cByJ mice is due to a deletion in the short-chain acyl-CoA dehy- drogenase gene and results in missplicing of mRNA. Genomics. 16:605-611.

29. Kelly, C.L., and P.A. Wood. 1996. Cloning and characterization of the mouse short-chain acyl-CoA dehydrogenase gene. Mamm. Genome. 7:262-264.

30. Prochazka, M., and E.H. Leiter. 1986. A null activity variant found at the butyryl CoA dehydrogenase (Bcd-1) locus in BALB/cByJ subline. Mouse News Lett. 75:31.

31. Reue, K., and R.D. Cohen. 1996. Acads gene deletion in BALB/cByJ mouse strain occurred after 1981 and is not present in BALB/cByJ-fld mutan mice. Mamm. Genome. 7:694-695.

32. Collins, S., C.M. Kuhn, A.E. Petro, A.G. Swick, B.A. Chrunyk, and R.S. Surwit. 1996. Role of leptin in fat regulation. Nature. 380:677.

33. Moinat, M., C. Deng, P. Muzzin, F. Assimacoupoulos-Jeannet, J. Seydoux, A.G. Duloo, and J.-P. Giacobino. 1995. Modulation of obese gene expression in rat brown and white adipose tissues. FEBS Lett. 373:131-134.

34. Kozak, L.P., U.C. Kozak, and G.T. Clarke. 1991. Abnormal brown and white fat development in transgenic mice overexpressing glycerol 3-phosphate dehydrogenase. Genes Dev. 5:2256-2264.

35. Zhou, Y.-T., M. Shimabukuro, K. Koyama, Y. Lee, M.-Y. Wang, F. Trieu, C.B. Newgard, and R.H. Unger. 1997. Induction by leptin of uncoupling protein-2 and enzymes of fatty acid oxidation. Proc. Natl. Acad. Sci. USA. 94: 6386-6390.

36. Wood, P.A., B.A. Amendt, W.J. Rhead, D.S. Millington, F. Inoue, and D. Armstrong. 1989. Short-chain acyl-coenzyme A dehydrogenase deficiency in mice. Pediatr. Res. 25:38-43.

37. Nada, M.A., W.J. Rhead, H. Sprecher, H. Schulz, and C.R. Roe. 1995. Evidence for intermediate channeling in mitochondrial beta-oxidation. J. Biol. Chem. 270:530-535.

38. Roe, C.R., and P.M. Coates. 1995. Mitochondrial fatty acid oxidation disorders. In The Metabolic and Molecular Bases of Inherited Disease, Vol. 1. C.R. Scriver, A.L. Beaudet, W.S. Sly, and D. Valle, editors. McGraw-Hill, Inc. New York. 1501-1533.

39. Dreyer, C., G. Krey, H. Keller, F. Givel, G. Helftenbein, and W. Wahli. 1992. Control of the peroxisomal $\beta$-oxidation pathway by a novel family of nuclear hormone receptors. Cell. 68:879-887.

40. Kliewer, S.A., B.M. Forman, B. Blumberg, E.S. Ong, U. Borgmeyer, D.J. Mangelsdorf, K. Umesono, and R.M. Evans. 1994. Differential expression and activation of a family of murine peroxisome proliferator-activated receptors. Proc. Natl. Acad. Sci. USA. 91:7355-7359.

41. Tontonoz, P., E. Hu, R.A. Graves, A.I. Budavari, and B.M. Spiegelman 1994. mPPAR $\gamma$ : tissue-specific regulator of an adipocyte enhancer. Genes Dev. 8:1224-1234.

42. Puigserver, P., Z. Wu, C.W. Park, R. Graves, M. Wright, and B.M Spiegelman. 1998. A cold-inducible coactivator of nuclear receptors linked to adaptive thermogenesis. Cell. 92:829-839.

43. Aubert, J., O. Champigny, P. Saint-Marc, R. Negrel, S. Collins, D. Ricquier, and G. Ailhaud. 1997. Up-regulation of UCP-2 gene expression by PPAR agonists in preadipose and adipose cells. Biochem. Biophys. Res. Commun. 238:606-611.

44. Aoyama, T., J.M. Peters, N. Iritani, T. Nakajima, K. Furihata, T. Hashimoto, and F.J. Gonzalez. 1998. Altered constitutive expression of fatty acidmetabolizing enzymes in mice lacking the peroxisome proliferator-activated receptor $\alpha(\mathrm{PPAR} \alpha)$. J. Biol. Chem. 273:5678-5684.

45. Lee, S., T. Pineau, J. Drago, E.J. Lee, J.W. Owens, D.L. Kroetz, P.M. Fernandez-Salguero, H. Westphal, and F. Gonzalez. 1995. Targeted disruption of the alpha isoform of the preoxisome prolifertor-activator receptor gene in mice results in abolishment of the pleiotropic effects of peroxisome proliferators. Mol. Cell. Biol. 15:3012-3022. 